\title{
Prisms of Pathos: Environmental Memes as a Public Rhetorical Strategy in the Example of Haze-Related Duanzi in China
}

\author{
Ling Liu* \\ School of Film Television \& Communication, Xiamen University of Technology, Xiamen, Fujian \\ *Corresponding author. Email: 35413972@qq.com
}

\begin{abstract}
The literature on environmental rhetoric has focused on texts produced by traditional news media. However, digital texts, such as Internet memes, are increasingly being written by citizens for the public sphere. This study investigated practices of public environmental rhetoric in China, a society with relatively limited free speech.Considering that analysis is difficult due to the speed, scale, and context of how memes publicly expressing environmental rhetoric circulate digitally, we used haze-related Duanzi, a popular meme on the Chinese Internet, as an example. Our analysis of digital rhetoric adopted a multiple-method design. The public's digital environmental rhetoric strategies pathos, in the context of network regulation, were traced and found to primarily feature appeals to the emotion of "confrontation-patriotism." We found that although the production and dissemination of Internet memes only weakly stimulated public participation in environmental protection activities, they enabled emotional venting and increased environmental awareness.
\end{abstract}

Keywords: Environmental Rhetoric, Haze-related Duanzi, Internet memes, Neo-Aristotelean Criticism, Pathos.

\section{INTRODUCTION}

Issues pertaining to health and the environment are not only complex, scientific issues but also weighty social ones. Generally, in China, large-scale citizen action is only triggered by issues that closely implicate the interests of every citizen. Haze is one such issue: it harms one's health, darkens the sky, paralyzes traffic, and affects everyone regardless of social strata.

Large-scale haze occurred in China in the autumn and winter of 2015, triggering online Duanzi (a way of expressing humor through words or pictures) about haze. Such expressions were especially popular, across all strata of society, as entertainment during the period of strong haze. Jokes expressing complaints through a combination of pictures, words, and emoticons swept the Internet, and songs based on these jokes have been composed. Such text evolved from commentary on air quality and haze governance to complaints. The lyrics of popular songs, such as "Beijing and Beijing" and "Parallel Galaxies," were rewritten with the theme of haze. The rewritten version of "Rolling up the Beaded
Curtain" had the following lyrics: "pedestrians on the road can't find their way north, and 'bricklayers' (An ironic expression of the experts) have covered their mouths, daring to ask who is responsible for the pollution." These comments were used to mock the government's response to the haze. In recent years, severe haze has continually been the butt of jokes made by Internet users and has become a popular theme in public discourse.

The meme was originally a natural-scientific concept, formulated by Dawkins in his pioneering 1976 book The Selfish Gene. For Dawkins, the meme (as the cultural counterpart of genes) was integral to the genetic basis of cultural evolution. Distin (2005) investigated meme replication, variation, and selection by comparing cultural transmission with gene evolution. Despite its evolutionary-biological etymology, the meme has been more recently used to refer to the dissemination of ideas and images through new media.

Shifman (2014) updated Dawkin's definition of the meme to be "a single cultural unit" of successful 
reproduction and defined Internet memes as "(a) a group of digital items sharing common characteristics of content, form, and/or stance, which (b) were created with awareness of each other, and (c) were circulated, imitated, and/or transformed via the Internet by many users" (p. 41). Internet memes refer to things that are a "faddish joke or practice...that become widely imitated" and "appear to spread and mutate via distributed networks in ways that the original producers cannot determine and control" (Burgess, 2008, p. 101). The specific manifestations of Internet memes on social media are viral videos, photographs, phrases, and strategic communication activities. In addition to exploring the rhetorical concept of the meme, Ballard (2018) proposed a rhetorical definition of the meme in his doctoral dissertation.

Once produced, haze-related Duanzi spread quickly the way viruses do and is therefore an example of an Internet meme, at least with respect to diffusion characteristics. Humorous, satirical, or novel Duanzi memes are produced, imitated, iterated, and cocreated by netizens. These memes skirt Chinese Internet regulations and are produced and spread in a surreptitious and critical manner. For example, a meme based on Journey to the West, a well-known folk tale, satirizes the severity of haze by relating the haze to the protagonist, a monk named Tang, and his three apprentices (Figure 1). Because haze adversely affects people's health, in addition to decreasing visibility, the meaning of "West" - a place where the characters find truth in the folk tale-was changed to a place where they find death.

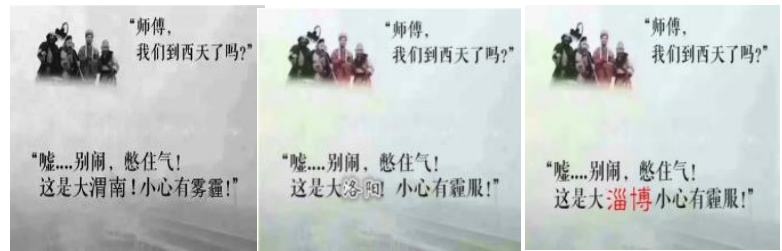

Figure 1 Meme of Journey to the West.

In China, public environmental discourse is regulated by the Chinese government. Commercial Chinese news media are still state owned and are expected to function as the ideological apparatus of the state. Environmental information and research on environmental communication are unlikely to deviate from the state's narrative due to such authoritarianism. Despite such authoritarianism, haze-related Duanzi can be produced and spread as memes in China, a country with strict Internet control. Because haze has become a public issue, the spread of haze-related memes has constituted rhetorical action. Our understanding of environmental communication in China will be patchy unless we understand how the public perceives environmental problems and consumes media representations of the environment and environmental problems (Tong, 2017). Memes give insight into the rhetoric of China's present-day grassroots environmental movement. Specifically, the rhetoric of Internet memes, in the form of haze-related Duanzi, explain the success of antihaze strategies adopted by Chinese Internet users.

Neo-Aristotelean criticism was developed by rhetorical critics on the basis of Aristotle's theory of rhetoric, foundational to the classical rhetorical school. Aristotle's definition of rhetoric is "the art(techne) of finding out the available means of persuasion" (trans. 1991). Persuasion strategies in classical rhetoric have been included in many recent rhetorical analyses to clarify the importance of ethos, pathos, and logos, Aristotle's three types of so-called artistic proofs.

In previous studies on environmental rhetoric, rhetorical analysis has been applied to numerous environmental situations in which individuals have attempted to create communities by combining logos with pathos. The ethos of environmental discourse has been reviewed by many rhetoric scholars, because it requires citizens to sacrifice their own interest for the greater interest. However, little attention has been paid to the use of pathos in environmental rhetoric, the effect of pathos on public participation, and whether pathos effectively stimulates public environmental protection behavior.

A meme may be compelling because of the credibility (ethos) of its content creator or social media user or the logic (logos) underlying the meme's message, with this logic spurring a visceral reaction. I argue that although these elements may contribute to the contagious nature of memes, it is pathos, the emotional appeal, that causes Internet users to read, react to, and (possibly) recoil from environmental content. Using the aforementioned studies as a basis and taking the cultural phenomenon of haze-related Duanzi in China as an example, this study regards Internet memes as a basic unit of cultural communication and explores the main rhetorical strategies employed in haze-related Duanzi. This study contributes to research on environmental rhetoric in China, a topic of theoretical and practical significance.

\section{LITERATURE REVIEW}

\subsection{The Meme as a Concept in Environmental Rhetoric}

The biologist Richard Dawkins first proposed the term meme as "a noun that conveys the idea of a unit of cultural transmission, or a unit of imitation." (p. 192). Memes first became an independent field of research in the 1980s and has remined active since.

Memetics is the study of memes and other cultural units. From the original theories postulated by Dawkins, Blackmore, Dennett, and others, the idea of a general meme emerged, as exemplified by the aforementioned 
quote by Robert O. Work. The "Internet meme" aptly describes digital text disseminated online. After years of Internet memes going viral, the term "meme" has come to be associated with one particular genre, the image macro (Ballard, 2018, p. 9).

According to some scholars, Internet memes can be used to analyze discourse at the macro level by regarding Internet memes as a form of micro-level discourse. Specifically, the influence of Internet memes is evident at the macro level, although Internet memes are spread, by individuals, at the micro level. People's beliefs, behaviors, and collective actions are influenced by Internet memes. Ballard's (2018) definition of a meme can be used for the rhetorical investigation of meme-like artifacts, whether through close reading or discourse analysis. As stated by Ballard, a meme is "a group of intertextual artifacts that explicitly or implicitly refer to each other through the sharing of alphanumeric, visual, or audio content, genre(s) or form(s), and/or an acknowledgment of a social phenomenon" ( p. 129).

Internet memes, as a rhetorical product with dynamic rhetorical characteristics, exhibit a wide spectrum of cultural participation and communication and have been broadly adopted by Internet users. These users have a clear rhetorical motive to call their digital creations "memes" because they constantly make these memes for various audiences and purposes. The Internet meme has many facets that make them better understood through rhetorical theory than Dawkins' biological one. As stated by Milner (2016), "Dawkins'...genes may be selfish, but his memes are social" (p. 41).

According to Davis, Glantz, \& Novak (2016), the concept of the meme explains the relationship between information circulation and Internet environmental rhetoric; in particular, they noted how Greenpeace sparked a grassroots online campaign with the theme "Let's Go!" by imitating the advertising form of Shell, the oil company. Greenpeace used satire and humor cleverly, and a series of Internet memes were generated, resulting in a halt to Shell's Arctic oil drilling program. An (2014) situated meme theory in the context of the Chinese Internet, analyzing how netizens spread and created memes on social change while under stringent Internet censorship.

In summary, memes enable the expression of individuality. With respect to environmental issues, the individual efforts of citizens are connected through memes to form collective action. Therefore, in addition to being an important cultural phenomenon, memes are useful analytical tools in digital rhetoric research in general and research on haze-related Duanzi in particular.

\subsection{Environmental Rhetoric}

Environmental rhetoric is defined by Killingsworth (1996) as "the subject or field of rhetorical practice, focusing on the relationship between people and the natural environment and dealing with discourse forms or systems of political and ethical disputes arising from environmental protection and development planning" (p. 225).

The literature on environmental rhetoric has focused on Static context and limited texts produced by traditional news media.The speed, scale, and context of digital circulation makes the context-specific analysis of the environmental rhetoric of image-text combinations difficult. Moreover, the personal writing mode in environmental rhetoric is changing to the public writing mode due to the emergence of digital texts such as Internet memes.

\subsection{Classical Rhetorical Theory}

Digital texts are collectively created by members of the public. However, classical rhetorical theory analyzes texts in the form of speech uttered (i.e., created) by the individual. Therefore, rhetoricians should consider whether classical rhetorical theory is applicable to the analysis of digital texts.

Some scholars argue that neo-Aristotelean criticism can never be applicable to the digital environment, whereas other scholars argue that it is applicable but only after reinterpretation. For example, Shen resituated Aristotelean rhetoric from individual-level public persuasion to communal care (Shen, 2007, p. 216). Aristotle believed that three kinds of artistic proofs existed in rhetoric, namely, the three persuasive means of ethos, pathos and logos.

"Ethos meant the character of a person (in terms of its correspondence to the values of his society)" (Conrad \& Malphurs, 2008). Phrases such as "a person like me" are exhibitions of ethos (Auger, 2014).

Pathos is persuasion through appeals to the audience's emotions, such as humor, happiness, sadness, satisfaction, love, and fear. These emotions must be "the deepest desires that define a human being, not the superficial emotions felt by a person in response to particular events" (Conrad \& Malphhurs, 2008, p. 127). Burke (1966) claimed that identification or socialization can be used to indicate the speaker's understanding of an audience's needs, values, and desires.

Logos refers to the clarity and rational integrity of an argument (Holt \& MacPherson, 2010). Emphasizing logic, $\log o s$ is a means of persuasion based on facts. Logos also encompasses the emergence of rationality or common sense that does not require persuasive evidence (Higgins \& Walker, 2012). 
Therefore, classical rhetoric should be applied to all rather than some forms of public discourse, including discourse on haze in particular and environmental discourse in general. Rhetoricians hold that the Aristotelean framework is the most complete system for analyzing and creating discourse, and rhetoric concepts must expanded as the possible means of communication become more diverse, with which the present author agrees. Although colloquial language is the source of classical rhetoric, digital rhetoric has become an essential means through which the public can participate in environmental discourse. Therefore, to investigate practices in digital environmental rhetoric, researchers must update the theory of classical rhetoric.

\section{METHODS}

According to Vankooten (2016), because the digital texts analyzed by rhetoricians are complex, diverse, and fleeting, a new hybrid methodology should be developed and interdisciplinarity should be emphasized.

This exploratory study uses mixed methods to examine online haze-related Duanzi in China. The methods are as follows: (1) text mining analysis, extended to digital text through four links-data acquisition, data organization, keyword analysis, and data visualization; (2) meme analysis, in which creative digital research and traditional qualitative strategies are employed to explain the circulation, transformation, and results of digital texts and explore the dynamic rhetorical process of digital haze-related discourse; and (3) fantasy-theme analysis, in which the group consciousness of haze issues are summarized according to the nodes of characters, scenes, and actions in semantic network analysis and full text sampling.

\subsection{Text Mining Analysis}

The methodology of this study is based on Ignatow and Mihalcea's 2016 book Text Mining: A Guidebook for the Social Sciences. This study's methodological steps were as follows.

\subsubsection{Data Acquisition}

In this study, keywords related to the research topic were used to mine digital texts of haze-related Duanzi on social media, with the mining performed using a web crawler. Micro blog samples were the main source of digital texts in this study, and the search period was December 1-31, 2015. In this study, 2376 digital texts on haze are obtained; the 60 haze-related Duanzi with the most likes (get the highest number of "likes" and "commenting"), crawler-captured data pertaining to sharing and commenting on the micro blogs were extracted for tracking analysis, and the micro blog texts with haze-related Duanzi as the subject words were extracted from the blog website obtained by the crawler. The WeChat platform was a data source in this study. Sogou WeChat official search was used to collect hazerelated Duanzi articles in the WeChat Official Account; the search term "haze-related Duanzi" was used, and manual segmentation, coding, and further analysis were subsequently performed. In this study, articles posted on December 2015 were selected, more than 100 types of haze-related Duanzi, with no repetition and different subjects, were analyzed, and 767 articles on haze-related Duanzi were obtained from the WeChat Official Account.

\subsubsection{Data Organization}

For Chinese text, the data sorting performed in this study was divided into word breaking and filtering. Digital texts were imported using Ncapture in QSR NVivo 12, automatic word frequency analysis is performed, and to eliminate interference, manual processing was used to filter words unrelated to the research topic as stop words.

\subsubsection{Keyword Analysis}

Keyword analysis establishes the relationship between word structure and the research topic, through rules such as word frequency, collocations, and parts-ofspeech classification. In this study, Ncapture in QSR NVivo 12 software was used to capture and import digital texts posted on social media, conduct automatic word frequency analysis, and manually process words irrelevant to the research topic into stop words to eliminate interference.

\subsubsection{Data Visualization}

For a first analysis, QSR NVivo 12 software was used to study the text. The data were then visualized through methods such as a text cloud.

\subsection{Meme Analysis}

Memes can be considered a participatory practice of producing texts, which can be rhetorically analyzed. According to Blakesley (2004), memes are a form of film rhetoric; the interactions among the anonymous creator, meme, meme iteration, and audience combine in this rhetoric form to create "the overall behavior that produces meaning" (p. 116).These elements(creator, meme, meme iteration, and audience) roughly correspond to the elements of the basic communication mode. However, memetic rhetoric involves not only the message, its sender, and its receiver but also the background of the event to which the meme is a response as well as the mixed text in the meme. Memes are endowed with rhetorical power by these relationships. For rhetorical critics, memes are a 
potential tool for digital environmental rhetorical analysis.

\subsection{Fantasy-Theme Analysis}

Recent methods in traditional rhetorical criticism have been combined with computing tools. For example, the concept of digital rhetorical criticism was first proposed by Gibbons and Seitz (2017), who combined ideographs in ideological criticism with digital tools (p. 171). Similarly, Tsao, Huang, and Liu (2017) studied digital texts by taking the word in the text as the basic unit and using methods in rhetoric criticism such as fantasy-theme, critical discourse, and big data analyses. Fantasy-theme analysis is a critical method of digital rhetoric in this study and is based on the theory of symbolic convergence proposed by Ernest E. Bormann. The four basic theoretical concepts of fantasy-theme analysis are the fantasy theme, chaining, the fantasy type, and rhetorical vision.

Scholars have summarized the methodological steps in fantasy-theme analysis as follows. (1) The text data generated through symbol convergence, including obvious and hidden pictures and texts, are collected by researchers. (2) Recurring fantasy themes are identified. The text is examined verbatim, and any possible fantasy themes are found. (3) The types of drama elementssuch as characters, plots, scenes, and actions-that appear repeatedly in the materials are summarized. (4) The fantasy types are discovered from the fantasy themes, and the rhetorical vision is constructed. (5) The sanctioning agent and deep structure behind the rhetorical vision are defined (Bormann, 1972, 1982; Foss, 1996; Yu, 2006).

\section{RESULTS FOR RHETORIC ANALYSIS OF HAZE-RELATED DUANZI IN CHINA}

Waddell (1996) believed that public participation was constituted by the social structure of the pathos of experts and nonexperts and reported that pathos effectively persuades stakeholders to take action (p. 15). The rhetorical content used by three nonprofit organizations on Twitter was explored in an environmental rhetorical study, and ethos was found to be the most prominent element in the persuasion model, being present in more than $90 \%$ of tweets (Smitko, 2012, p. 633).

How persuasion strategies can be employed to influence the thoughts, emotions, and behavior of social actors has been demonstrated in various studies (Higgins \& Walker, 2012). In the aforementioned studies on environmental rhetoric, three persuasion strategies have mainly been used to rhetorically analyze environmental texts, particularly in verifying the persuasive effectiveness of logos and pathos in promoting public environmental protection behavior.
These studies have also verified the effect of ethos in environmental rhetoric persuasion strategies with respect to public participation. In this study, I argue that pathos is used as a digital environmental rhetorical strategy.

\subsection{Pathos Used as a Digital Environmental Rhetorical Strategy}

Memes can influence a person's emotions or attitude, and understanding this influence constitutes a crucial step toward understanding how memes affect politics through their ability to persuade voters (Huntington, 2016). Memes do not convey logical, moral, or even complete arguments but exert considerable control through people's emotions (Amy, 2019, p. 9). Pang and Law (2017) demonstrated a significant correlation between the use and forwarding of memes involving ethos and pathos.

Weaver stated that pathos is the core of rhetoric (Bizzell \& Herzberg, 2001), and is an indispensable part of social media content. According to Brinton (1988), the largest difference between the rhetoric of Aristotle and a sophist is that the sophist regards pathos as only an object of incitement, whereas Aristotle regards it as part of the faculty of rational judgment.

Aristotle noted three means of persuasion in his discussion of rhetoric, of which pathos is one. Aristotle (trans. 1991) mentioned that pathos is executed through the use of vivid descriptions, honorifics, or derogatory words. Aristotle's Rhetoric contains a systematic theory of emotion. According to Aristotle, in addition to considering how to make speech have the power of proof and persuasion, the speaker must judge the audience's mood, which greatly enhances persuasion (Aristotle, 1926, translated by Yan Yi and Cui Yanqiang, 2003, p. 1378a).

Therefore, the speaker must not only understand but also influence emotions. Various important emotionssuch as fear, anger, shame, righteous indignation, and pity-are defined by Aristotle in Chapters 2-11 of Volume 2 of Rhetoric. For example, he defined fear as a type of pain or uneasiness that arises from the idea of a coming disaster (Aristotle, 1926, translated by Yan Yi and Cui Yanqiang, 2003:1382a). In "pathos rhetoric," "an actor tries to persuade others by activating their emotions such as fear, anger, shame, jealousy, and so on" (Ery1lmaz, 2014, p. 293).

Jenkins (2014) argued that the rhetorical analysis of memes "obliged a shift from the actual-particular texts in specific contexts - to the virtual" (the capacities for affect and affection structuring an encounter; p. 443). Therefore, we believe that in addition to reading texts for their meaning, rhetoricians conducting modal analysis must evaluate the text's relation to emotion. 
When analyzing the fantasy themes of typical hazerelated Duanzi memes, we noted many rousing words in both the top 100 word frequency fantasy-theme vocabulary entries and summarized fantasy themes (scene and action themes). For example, (1) in the "promoting national security" meme, the action-theme words included nonsuch, bricker, Duanzi dog, out of context, serious, nonsense, deception, shameless, hard work, like, powerful, fierce, humorous, witty, lovely, happy, misunderstanding, prejudice, and reassurance. (2) In the "Chai Jing's documentary is banned" meme, the action-theme words included horror, accusation, swearing, satire, and hope. (3) The action-theme words in the "dead rising" meme included horror, terror, fear, panic, severity, funny, and exciting. (4) The actiontheme words in the "Beijing, Tianjin, and Hebei residents have to have good lungs" meme included hold on, helplessness, escape, good, and worry free. These examples reveal that in addition to carrying rhetorical vision, memes on environmental issues, created by the public in the digital era, convey many emotions. Therefore, it is of great theoretical and practical significance to analyze the transmission process of hazerelated Duanzi memes and explore the pathos employed in them.

\subsection{Appeals to the Emotional Logic of Confrontation-Patriotism}

In recent years, quantitative emotion analysis, involving tools such as emotion dictionaries, has been used in many studies on emotion. The haze-related Duanzi memes investigated in the present study appealed to emotion rather than to reason or the credibility of the meme creator. The present study is mainly based on Aristotle's definition of several important emotions. Aristotle considered words that stirred sadness, doubt, fear, anger, gentleness, shame, and righteous indignation in Rhetoric (Aristotle, 1926, translated by Yan Yi and Cui Yanqiang, 2003, p. 1378a1388b). In this study, a Chinese ontological emotion lexicon (Xu Linhong, et al., 2008) was used as a Chinese emotion evaluation dictionary for analyzing the emotional rhetoric of specific memes. We found that the memes' circulation process generally exhibited the emotional logic of appealing to confrontationpatriotism.

\subsubsection{Appeals to the Emotion of Confrontation}

We found that, to resist public officials and the government, who possess discursive power; memes were used to arouse negative emotions.

\subsubsection{Public-Government Antagonism}

Shame is defined by Aristotle as a type of pain or uneasiness related to past or future events that negatively affect one's reputation. Thus, by this definition, people necessarily feel shame for themselves or those they care about when considering reputationharming events (Aristotle, 1926, translated by Yan Yi and Cui Yanqiang, 2003, p. 1383b). Our rhetorical analysis of the meme template "Mayor - Joke" in hazerelated Duanzi indicated a logic of confrontation between the public and government through appeals to the emotion of shame.

Shame is regarded by Aristotle to be perceived rather than actual dishonor (ibid. p. 1384b). The "Mayor - Joke" memes are a series of memes centered on Wang Anshun, the former mayor of Beijing, whose message is that government officials should be ashamed of their inability to effectively manage haze. The first picture on the left in Figure 2 shows Wang Anshun making the promise at a press conference, "if I can't get rid of the haze, I'll see you with my head (a Chinese idiom indicating resolution to complete a task on pain of death)," and this is accompanied by text saying "it is actually a joke, hahaha." The scene-theme was reflected by this picture, whereas the blame placed by netizens on him for his dishonest behavior is expressed by the text, which reflects the poor reputation of government officials in the eyes of the public. The middle part of Figure 2 shows the picture and text on the left together with a comment left by a netizen-"the picture comes from people.cn (the official online media)"- expressing that this meme was not created out of nothing. Furthermore, text was added at the bottom-"they were afraid not only of leaders but also of haze" to express that government officials should be ashamed and condemned by the public for their boasting and misbehaving.

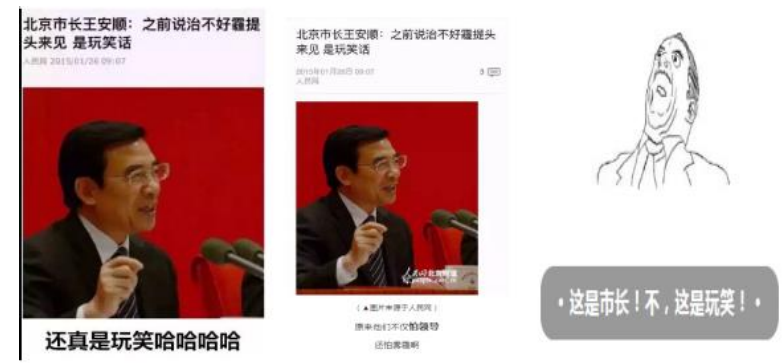

Figure 2 "Mayor · joke" meme

\subsubsection{Public-Expert Antagonism}

In the present context, doubt is defined as questioning of elite discourse on haze governance, particularly by the government, experts, and scholars. For example, the "haze protects against laser weapons" meme appeals to the antagonism between experts and the lay public by expressing the emotional appeal of doubt.

The "haze protects against laser weapons" meme aims to present such negative words as "nonsense" (扯 
淡 in Chinese, which has the same literal meaning as its English counterpart) and "bullshit"(胡说八道 in Chinese, which has the same literal meaning as its English counterpart) through the comments on a TV program of expert Zhang Zhaozhong regarding how haze can prevent lasers, although a few netizens supported Professor Zhang Zhaozhong. In the meme, the negative rhetorical vision of Duanzi creators are summarized as follows: (1) the expert's claim that haze improves national defense is nonsense; (2) the claim that haze protects local security is bullshit; and (3) the haze-free area (the south) abandoned in the strategy of defense is really good. These three rhetorical points can be summarized into one point: that the haze improves national defense is nonsense. Doubt is the main manifestation of negative emotion and indicates that the vast majority of netizens disapproved of scientific discourse produced by the mainstream media.

With respect to negative emotions, the meme is realized by the netizens second-guessing claims about the haze, identifying the negative or skeptical attitude of relevant experts in the mainstream media, and adapting and disseminating original screenshots. The meme text indicates that the meme was created to deny the veracity of the expert's scientific discourse by emphasizing that the expert's remarks that "haze poses a great threat to laser-based weapons" are bullshit, nonsense, and shameless. In the left picture in Figure 3(a), the meme template, showing the controversial TV show "Cross Strait," is shown, allowing skepticism to form in the viewer regarding the expert's remarks. In the picture on the right, a self-made comic was used to reflect the strong disapproval of netizens. It is this type of satire that can humorously subvert experts' ideological views while helping to highlight the ideology of meme makers.

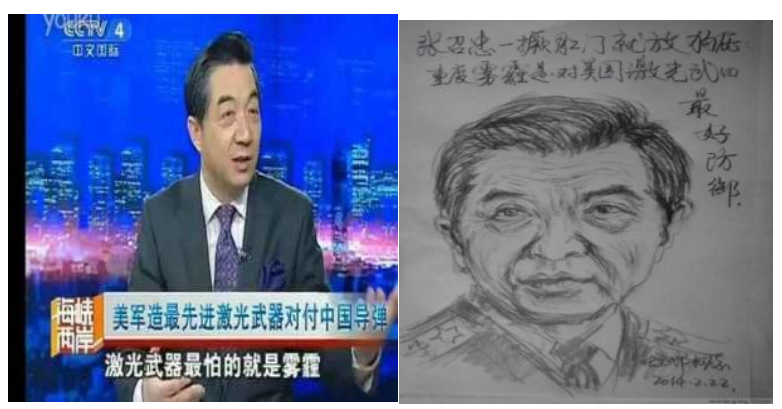

Figure 3(a) "haze protects against laser weapons" meme

\subsubsection{The North-South Distinction}

Anger was defined by Aristotle as "an obvious revenge accompanied by painful desire and aroused by obvious neglect," and he also stated, "in every anger, there is a certain happiness, which comes from the strong desire for revenge" (ibid. p. 1378b). The "Beijing, Tianjin, and Hebei need good lungs" memes mainly appeals to the emotion of anger. Antagonism between the north and south is emphasized to attract the participation of netizens from all over the country.

The fantasy-theme analysis revealed that the role theme words in the "Beijing, Tianjin, and Hebei must have good lungs" memes were mainly northern cities such as Beijing and Tianjin and those in Hebei, Shaanxi, Gansu, Liaoning, Jilin, and Heilongjiang province. The scene-theme words mainly include "lungs must be good," new specialty "haze," and "unbearable." Negative emotions are the main manifestations of emotional appeals in these memes, that is, anger caused by haze that leads to poor health. People's desire for comprehensive management of haze to ensure breathing safety is not satisfied, so the people are accustomed to being angry at the government's neglect or contempt. In this case, the authorities have naturally become "scapegoats," that is, targets who must bear people's anger. Therefore, the "Beijing, Tianjin, and Hebei need to have good lungs" memes appeared and resonated with people in other areas experiencing severe haze; the memes were then repeated, such as in the "Shan-GanNing must have good lungs" and "Liao-Ji-Hei must have good lungs" memes, to express anger. As the user of rhetoric, the originator and co-founder of the Duanzi induces the audience to enter a mood in which they are prone to anger and likely to spread the haze-related Duanzi. The audience considers the administration to be causing anger in the people.

When tracing the "Beijing, Tianjin, and Hebei must have good lungs" memes, the role theme of the meme is discovered to also be reflected in southern cities of Shenzhen and Guangzhou and in Fujian. "Big sun," "unbelievable winter," and "free air" are the main themes of the scene. The status of netizens in the south being superior to that of citizens in the north is expressed; that is, those in the south feel that the air is good and they can breathe carefree. Therefore, netizens from all over the world are attracted to the antagonism of the north versus the south as the meme is widely spread.

\subsubsection{Appeal to Patriotic Feelings}

When the memes were rhetorically analyzed, they were discovered to appeal to the patriotic sentiment of the majority of netizens, to enhance the participation of these netizens, as well as to exacerbate multiparty antagonism. The following three main aspects were noted. At the national level, strong patriotic feelings were appealed to through the invocation of an "American conspiracy theory" in memes such as "Chai Jing's Documentary is banned;" at the regional level, the patriotic feelings of holding the position are expressed in memes such as "Beijing, Tianjin, and Hebei must have good lungs"; and at the personal level, support of public figures who transmit mainstream values to 
maintain the harmony and stability of the country is expressed through memes such as the "haze protects against laser weapons" memes.

\subsubsection{National Level}

When analyzing the fantasy themes for the "Chai Jing's documentary is banned" memes, the "American conspiracy theory" is found to be the most common fantasy type. The four most common keywords in these memes are "America," "problem," "China," and "Beijing." Clicking on these four keywords in the Nvivo12 software document to show the original comments revealed emotion words such as "conspiracy," "patriotism," and "attack" in the corresponding action words. Some netizens demonstrated patriotism in their memes and reported that the documentary Under the Dome, filmed by Chai Jing, was part of a conspiracy among developed countries such as the United States, with the purpose of this conspiracy being to maintain the socialist system, dictatorship of the proletariat, and national interest.

When the sanctioning agents and the deep structure behind the memes are traced, the concepts of prosperity, democracy, and civilization in the core values of socialism were found to have become the sanctioning agents for shaping rhetorical vision in the memes. In addition to stating that many people affirm the contribution of Chai Jing and the corresponding documentary, the "Chai Jing's documentary is banned" memes also pointed out another group of people in the process of recitation. This group was depicted as patriotic, and the meme criticizes Chai Jing for "fawning on foreign countries and seeking glory," believing that the motivation of Chai Jing and her production team was affected by various interested parties both at home and abroad. These people regard Under the Dome as a pawn used by foreign powers to discredit China and that it should be banned. The patriotic sentiment of the meme creators-expressing the hope that the motherland will stop the interference of foreign forces and become even more prosperous - is further demonstrated by the use of the deep structure of the drama.

\subsubsection{Regional Level}

Taking the "Beijing, Tianjin, and Hebei must have good lungs" memes as examples, we analyzed the fantasy themes of memes and found that the memes present different life experiences of citizens in the north and south during the haze season. The memes mainly appeal to "anger" and "gentleness," conveying patriotic feelings such as "stick with it" and "don't give up" in the north and "satisfaction" and "pride" in the south because the air is good in the south.
The plot lines of this meme mainly involve Beijing, Tianjin, and other northern cities with heavy haze such as those in Hebei, Shaanxi, Gansu, Ningxia, Liaoning, Jilin, and Heilongjiang. Major action themes of the memes are "hold on" and "stick with it." Pathos is mainly reflected by depictions of the patriotism of citizens in the north, who chose to "not give up" and "not become residents of an empty city" despite severe haze. This indicates a strong sense of national identity among Chinese citizens.

In addition to the role-themes for the northern region, a class of character themes was identified for southern cities, such as Shenzhen, Guangzhou, and those in Fujian. The themes of the scene were mainly "big sun," "don't believe in winter," and "no charge for air," whereas the action-theme words were mainly "good," "like," and "no worries." Further examination of these characters, scenes, and action-theme words indicated that the memes reflect the strong sense of national identity and belonging of southern citizens who enjoy clean air and a robust economy.

\subsubsection{Level of Public Opinion}

The "haze protects against laser weapons" memes strongly support the opinions of public figures transmitting mainstream values, which contribute to sociopolitical stability. The memes also elicit slightly positive emotions. The main scene themes are "experts are reasonable" and "Duanzigou should not create Duanzi." Some netizens expressed their dissatisfaction with the teasing of Zhang Zhaozhong. They consider "Duanzigou" to have been taken out of context and the main positive emotion attached to Zhang Zhaozhong to be "trust."

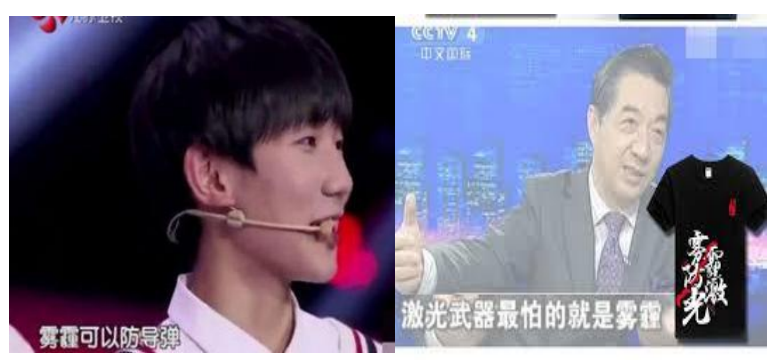

Figure 3(b) "haze protects against laser weapons" meme

The statement that "haze poses a great threat to laser-based weapons" aroused the doubts of netizens. Zhang Zhaozhong took the opportunity to appear live on Bilibili. Although the content of the live broadcast was the same as that of military programs recorded in the past, when he appeared in a T-shirt with white characters and a black background printed with "haze can prevent lasers," he attracted his greatest support thus far, which directly crashed the server of station B. Zhang Zhaozhong's statement that "haze protects against 
laser weapons" quickly went viral. Furthermore, many ghost videos are circulating on the Internet.

Although Zhang Zhaozhong is teased in the meme, we noted that young netizens loved Zhang Zhaozhong; in Figure 3(b), the image background was replaced with a photograph of Wang Yuan, a member of a popular youth idol group TFboys, during his participation in a variety show, and the words "haze can defend against missiles" was written; thus, the love for the youth group was employed to "roast" (make fun of) Zhang Zhaozhong in a humorous way. In the meme presented in Figure 3(b), the original image is faded and a black and white T-shirt with the words "haze protects against laser weapons" is added in the lower right corner. Moreover, many sellers on Taobao (an online marketplace) are offering $\mathrm{T}$-shirts bearing the words "haze can prevent lasers," and these products have become popular among young people.

\section{CONCLUSION}

By using digital rhetorical analysis to explore the types of emotion in haze-related Duanzi, a type of public opinion response, this study discovers that memes on the environment mainly appeal to emotions rather than to reason. Haze-related Duanzi link emotion with morality to influence the feelings of Internet users and make them participate in environmental issues by forwarding or creating memes. Memes can become powerful and be widely spread on social media. A crucial factor is whether a meme can successfully arouse strong emotions in other netizens. After analyzing relevant meme cases, this paper presents the following findings.

First, pathos is the primary rhetorical strategy in haze-related Duanzi and is used to express the anxiety of the general public under stringent Internet censorship in China. The rhetorical strategy of pathos used in the memes mainly involves appeals to confrontationpatriotism; this is reflected in the Internet users' online participation and the interaction between netizens and memes. The haze-related Duanzi memes are thus a game of confrontation-patriotism. The main reason a meme becomes popular is that it expresses many negative emotions such as anxiety and fear that are related to the haze problem and that it resonates strongly with other Internet users, who then participate in the creation and expansion of the haze-related Duanzi.

Second, it should be emphasized that haze-related Duanzi can play only a limited role in encouraging more people to participate in environmental protection activities if the production and dissemination of hazerelated Duanzi is regarded as an alternative expression of public environment rhetoric. However, the role of this Duanzi in providing an emotional outlet and increasing environmental awareness is beyond doubt.
Haze-related Duanzi has two potential functions: it not only humorously conveys the message that serious air pollution issues can be politicized but also indicates that an environmental problem can be converted to an online game. Some meme creators become immersed in wordplay and neglect to undertake concrete environmental protection action.

Third, the original purpose of creating a meme is to provide emotional catharsis. However, with the further cocreation and dissemination of haze-related Duanzi, some expressed mixed reactions because of their feelings of patriotism. In this instance, the negative emotion is partially resolved. In fact, the circulation of haze-related Duanzi has become part of a statesanctioned public space for the public to discuss sensitive issues. Specifically, the creation of Duanzi gives extremely dissatisfied netizens an emotional outlet, which functions as a pressure valve that preserves social stability.

Finally, with regard to environmental governance, this study provides empirical support for policymakers seeking to track public opinion and demands regarding environmental issues, steer public emotion through the Internet, and stimulate public environmental protection behavior in citizens.

\section{ACKNOWLEDGMENTS}

This research was supported by my doctoral thesis instructor Tzu-hsiang Yu, my classmates particularly Cheng Yu, and financially supported by 2019 Educational Research Project on the Young and Middleaged Teachers of Department of Education in Fujian Province (JAS19325).

\section{REFERENCES}

[1] A. Cole, (2019). Prisms of pathos: political memes in social media, Dr. Carter., Spring 2019 , Rhetorical Theory, Arkansas: UA Little Rock.

[2] X. M. An, (2014). Batman, pandaman and the blind man: A case study in social change memes and Internet censorship in China. Journal of visual culture, 13(3), 359-375.

[3] Aristotle, (trans. 1991). On rhetoric: A theory of civic discourse (G. A. Kennedy, Trans.). New York, NY: Oxford University Press.

[4] Aristotle. [1926]. Art of Rhetoric [VolumeXXII, J. H. Freese], Trans. Yan Yi and Cui Yanqiang (2003). Beijing, China: Renmin University of China Press.

[5] G.A. Auger, (2014). Rhetorical framing: Examining the message structure of nonprofit organizations on twitter. International Journal of 
Nonprofit \& Voluntary Sector Marketing, 19(4), 239-249.

[6] T. M. Ballard, (2018). Meme as a rhetorical concept for digital media genres (Doctoral dissertation). Retrieved from ProQuest. (ProQuest no. 10786671).

[7] P. Bizzell, B. Herzberg, (2001). The rhetorical tradition: Readings from classical times to the present. Second edition. Boston, MA: Bedford/St. Martin's.

[8] D. Blakesley, (2004). Defining film rhetoric: The case of Hitchcock's Vertigo. In C. A. Hill \& M. Helmers (Eds.) Defining visual rhetorics (pp.111133). N. J. Mahwah, : Lawrence Erlbaum Associates.

[9] E.G. Bormann, (1972). Fantasy and rhetorical vision: the rethorical criticism of social reality. Quaterly Journal of Speech, 58(4), 396-407.

[10] E.G. Bormann, (1982). A fantasy theme analysis of the television coverage of the hostage release and the Reagan inaugural. Quarterly Journal of Speech, 68(2), 133-145.

[11] A. Brinton, (1988). Pathos and the "Appeal to Emotion": An Aristotelian Analysis. History of Philosophy Quarterly, 5(3), 207-219.

[12] J. Burgess, (2008). 'All your chocolate rain are belong to us?' Viral Video, YouTube and the dynamics of participatory culture. In G. Lovink \& S. Neiderer (Eds.), Video vortex reader: Responses to YouTube (pp. 101-109). Amsterdam: Institute of Network Cultures.

[13] K.Burke, (1966). Language as symbolic action: Essays on life, literature, and method. London, England: University of California Press.

[14] C.Conrad, R. Malphurs, (2008). Are we there yet? Are we there yet?. Management Communication Quarterly, 22(1), 123-146.

[15] C. B. Davis, M.Glantz, D. R. Novak, (2016). "You can't run your SUV on cute. Let's Go!" Internet memes as delegitimizing discourse. Environmental Communication, 10(1), 62-83.

[16] R. Dawkins (1976). The Selfish Gene, New York, NY: Oxford University Press.

[17] M. E. Eryllmaz, (2014). Pathos rhetoric in vision statements of organizations: Findings from Turkey. Procedia-Social and Behavioral Sciences, 150, 291-299.

[18] S.K. Foss,(1996). Rhetorical Criticism: Exploration and Practice. Prospect Heights, Colorado: Waveland Press.
[19] M. G. Gibbons, D. W. Seitz, (2017). Toward a digital methodology for ideographic criticism: A case study of" equality". In Theorizing Digital Rhetoric (pp. 169-183). London; New York: Routledge.

[20] C. Higgins, R.Walker, (2012). Ethos, logos, pathos: Strategies of persuasion in social/environmental reports. Accounting Forum, 36, 194-208.

[21] R. Holt, A. Macpherson, (2010). Sensemaking, rhetoric and the socially competent entrepreneur. International Small Business Journal, 28(1), 20-42.

[22] H. E. Huntington, (2016). Pepper spray cop and the American dream: Using synecdoche and metaphor to unlock Internet memes' visual political rhetoric. Communication Studies, 67(1), 77-93.

[23] G.Ignatow, R.F.Mihalcea, (2016).Text Mining: A Guidebook for the Social Science. Loudon, UK: SAGE.

[24] E. S.Jenkins, (2014). The modes of visual rhetoric: Circulating memes as expressions. Quarterly Journal of Speech, 100(4), 442-466.

[25] M. J. Killingsworth, (1996). Environmental rhetoric. In T. Enos (Ed.), Encyclopedia of rhetoric and composition (pp. 225-227). New York, NY: Garland.

[26] R.M.Milner, (2016). The world made meme: Public conversations and participatory media.Cambridge, Massachusetts: MIT Press.

[27] N. Pang, P. W. Law, (2017). Retweeting\# WorldEnvironmentDay: A study of content features and visual rhetoric in an environmental movement. Computers in Human Behavior, 69, 5461.

[28] Jinhui Shen (2007). Electronic Rhetoric and Public Communication.Taipei: Wunan Press.

[29] L.Shifman, (2014). Memes in digital culture. Cambridge, Massachusetts: MIT Press.

[30] K.Smitko, (2012). Donor engagement through Twitter. Public Relations Review, 38(4), 633-635.

[31] Kai-Ming Tsao, Lin-Me Huang i, Ta-Hua Liu (2017). Digital rhetorical criticism and text mining tools: Taking anti-core Facebook fan groups to shape fantasy themes as an example, Research in Information Society, 32: 9-50.

[32] J. Tong, (2017). Environmental communication in and about China: a review of the Chinese-language literature. Chinese Journal of Communication, 10(2), 192-208. 
[33] C. Vankooten, (2016). Methodologies and methods for research in digital rhetoric. Enculturation: A Journal of Rhetoric, Writing, and Culture. Retrieved from http://enculturation.net/methodologies-andmethods-for-research-in-digital-rhetoric.

[34] C. Waddell, (1996). Saving the great lakes: Public participation in environmental policy. In C. G. Herndl \& S. C. Brown (Eds.), Green culture: Environmental rhetoric in contemporary America (pp. 141-165). Madison, WI: University of Wisconsin Press.

[35] Tzu-hsiang Yu (2006). Voices of the Leaders: Political and Rhetorical Criticism of Cross-Strait Leaders, 1906-2006". Taipei: Wunan Press.

[36] Linhong Xu, Hongfei Lin, Yu Pan, Hui Ren, Jianmei Chen (2008). The Structure of Emotional Lexical Ontology, Journal of Information, 27 (2): 180-185. 